\title{
Governo eletrônico e seus impactos na estrutura e na força de trabalho das organizações públicas
}

\section{Introdução}

Talvez seja novidade, para muitas pessoas, o fato de Einstein ter ganho um Prêmio Nobel de Física, em 1922, não por haver enunciado a teoria da relatividade, por ter forjado o conceito de "tempo-espaço" ou por haver demonstrado matematicamente a conversibilidade de matéria em energia $-\mathrm{E}=\mathrm{mc} 2-$ mas, de maneira surpreendente, por seu trabalho em relação ao efeito fotoelétrico.

Contudo, tenho certeza que não é novidade para ninguém o fato de vivermos em um período de rápidas mudanças, em que transitamos de uma sociedade salarial (Castells) para uma sociedade pós-industrial (Bell), onde as reestruturações tecnológicas e produtivas dão indicativos tanto da expansão do tempo livre (De Masi), do fim do trabalho como aspecto central das relações de produção (Offe), como de gerador de altas taxas de desemprego (Rifkin).

No âmbito governamental, verificamos que os processos de reforma e modernização da gestão pública estão enfrentando um novo desafio, qual seja, o de adaptarem-se à crescente difusão das inovações tecnológicas ${ }^{1}$ e à expansão de um novo paradigma produtivo associado ao estabelecimento da chamada "sociedade do conhecimento".

$\mathrm{Na}$ atual terceira revolução industrial, temos a biotecnologia, os novos materiais e as Tecnologias da Informação e de Comunicação (TIC) — principalmente as baseadas na microeletrônica, nas telecomunicações e no processamento de dados no ambiente Internet - como as responsáveis pelo surgimento de novos métodos de produção, novas formas de organização, novos produtos e novos mercados.
Espartaco

Madureira

Coelho é

economista e

especialista em

políticas públicas

e gestão

governamental,

atualmente

trabalhando na

Secretaria de

Gestão do

Ministério do

Planejamento,

Orçamento e

Gestão.

Contato:

espartaco.coelho@ planejamento.gov.br 
Neste sentido, com o intuito de promover uma maior utilização das TIC, por parte das administrações públicas, diversos governos criaram programas para a implantação da Sociedade da Informação, onde por meio de um documento chamado Livro Verde, propõem diretrizes para a estruturação de infra-estruturas de comunicação, regulação, educação e universalização de acesso ao ambiente digital, bem como para o desenvolvimento de ações governamentais que também promovam o incremento da sua eficiência e da sua transparência, por meio do uso intensivo destas tecnologias.

Depois que estas propostas são colocadas à disposição de outras áreas do governo, da iniciativa privada, da comunidade científica e da sociedade civil e têm validados os seus conteúdos, o plano resultante é consolidado no que costuma-se denominar de Livro Branco.

Nos processos de promoção de uma Sociedade da Informação, há um reconhecimento generalizado de que uma das estratégias mais importantes a ser adotada é a do desenvolvimento de ações voltadas ao estabelecimento de um governo adaptado às características e às necessidades de uma nova Era do Conhecimento, em que a adoção destas novas TIC venha a proporcionar melhorias nos processos de gestão interna e de prestação de serviços à sociedade.

Assim, temos que, sempre que as transações realizadas por governos, empresas ou indivíduos estão baseadas na plataforma Internet, estas são rotuladas como e-business ou "negócios eletrônicos". Sendo que para o âmbito das administrações públicas, foram cunhadas as expressões "governo eletrônico" ou, mais recentemente, "governo digital" ou "governo virtual" para designar "toda a prestação de serviços e informações, de forma eletrônica, para outros níveis de governo, para empresas e para os cidadãos, 24 horas por dia, sete dias por semana". ${ }^{2}$

A partir destes pressupostos, é natural que se formule um amplo questionamento sobre como a adoção das TIC influencia a estrutura, a forma de gestão, o capital humano e o desempenho das organizações públicas.

Desta maneira, este trabalho propõe-se a promover o debate e a fomentar a inserção destas questões nas pautas de discussão das administrações públicas, inicialmente, por meio de uma revisão das visões (Livros Verdes), dos programas (Livros Brancos) e das ações empreendidas para o estabelecimento de um governo eletrônico no Brasil, no Canadá, em Cingapura e no Reino Unido, ao mesmo tempo em que busca identificar aqueles aspectos relacionados às novas formas de gestão, de reestruturação do trabalho e à aquisição contínua de novos conhecimentos por parte das organizações e de seus recursos humanos.

Adicionalmente, como forma de ilustrar as vicissitudes enfrentadas em áreas de atuação e de conhecimento tão inovadoras quanto complexas, 
são apresentados dois estudos de caso, em que são examinados os impactos

sobre os processos organizacionais e sobre a força de trabalho em duas organizações públicas brasileiras - a Secretaria da Receita Federal (SRF) e o Instituto Nacional de Seguridade Social (INSS) - que, atualmente, ocupam posição de destaque na utilização das novas TIC.

\section{Quatro visões governamentais}

\section{Brasil}

As políticas e iniciativas do governo brasileiro para a estruturação de um governo eletrônico estão descritas, principalmente, em dois documentos: o Livro Verde, elaborado pelo Programa Sociedade da Informação no Brasil $^{3}$ e a Proposta de Política de Governo Eletrônico para o Poder Público Federal, ${ }^{4}$ elaborado pelo Comitê Executivo do Governo Eletrônico. Além disso, o governo federal desenvolveu um website ou endereço eletrônico exclusivo $^{5}$ onde estão disponíveis o histórico do comitê, a legislação pertinente, os documentos gerados, as notícias e os eventos relacionados ao assunto.

Em setembro de 2000, o Programa Sociedade da Informação no Brasil, subordinado ao Ministério da Ciência e Tecnologia, publicou o Livro Verde para divulgação e debate das diretrizes e das suas metas de implementação. Assim como em outros países que buscam definir políticas e prioridades rumo à Sociedade da Informação, o trabalho apresenta uma ampla descrição das oportunidades e riscos a serem enfrentados e desenvolve sete grandes linhas de ação:

a) mercado, trabalho e oportunidade;

b) universalização de serviços para a cidadania;

c) educação na sociedade da informação;

d) conteúdo e identidade cultural;

e) governo ao alcance de todos;

f) Pesquisa e Desenvolvimento (P\&D), tecnologias-chave e aplicações; e

g) infra-estrutura avançada e novos serviços.

Dentro da abrangência proposta por este trabalho - a de analisar os impactos do governo eletrônico nas estruturas organizacionais e na força de trabalho das administrações públicas — identificamos dois itens de aderência ao tema, neste documento: o Capítulo 2, relativo a mercado, trabalho e oportunidades e o Capítulo 6, que trata das ações do governo eletrônico.

No Capítulo 2, reservado à promoção da competitividade das empresas nacionais, ao apoio à implementação do comércio eletrônico e à oferta de novas formas de trabalho, há destaque para as propostas de uso 
da Internet (com assunção para o ambiente de governo eletrônico), para

o desenvolvimento de oportunidades de alfabetização digital, de capacitação técnica e reciclagem profissional, além da promoção de soluções de teletrabalho.

Apesar destas definições e diretrizes, as organizações públicas brasileiras ainda não possuem uma estratégia integrada e organizada de forma a preparar servidores e gerentes para a plena utilização das ferramentas e para o aproveitamento das oportunidades oferecidas pelas novas tecnologias, sendo, entretanto, prática consolidada a existência de programas permanentes de treinamento em microinformática, voltados à capacitação em aplicações de automação de escritório e de introdução ao ambiente Internet.

No Capítulo 6, dedicado à promoção da informatização dos serviços públicos, há destaque às ações de capacitação em gestão das TIC para os integrantes da administração pública.

Neste aspecto, cabe destacar a existência, no âmbito do governo federal, de uma ação voltada à capacitação de servidores públicos de alto nível, com a implantação de um curso de Especialização em Tecnologias da Informação e Comunicação (com módulos gerenciais e técnicos), elaborado pela Secretaria de Logística de Tecnologia da Informação e ministrado pela ENAP Escola Nacional de Administração Pública, ambas subordinadas ao Ministério do Planejamento, Orçamento e Gestão.

Em relação ao documento elaborado pelo Comitê Executivo do Governo Eletrônico e intitulado Proposta de Política de Governo Eletrônico para o Poder Público Federal, também de setembro de 2000, há um detalhamento de metas e macroobjetivos prioritários. Sob o objeto deste trabalho, merecem destaque as ações que direcionam para a obtenção de novos insumos quanto:

a) à mensuração e controle dos serviços prestados, seja:

- pela realização de pesquisas de qualidade e de satisfação dos usuários;

- pela medição do índice de atendimento às consultas e solicitações dos visitantes;

- pelo acompanhamento da tramitação de processos pela Internet; ou

- pela implantação de uma Ouvidoria, vinculada à Presidência da República; e

b) a novas formas de atuação da administração pública, com ênfase na:

- disponibilização de todos os serviços prestados no ambiente Internet;

- implantação de solução de call centre governamental integrada;

- institucionalização da modalidade de pregão eletrônico para a realização de compras governamentais;

- eliminação do uso do papel na documentação governamental; e 
- integração dos sistemas de gestão administrativa.

Todas estas ações já estão implementadas ou encontram-se em avançado estado de andamento, mas os seus impactos em relação a mudanças organizacionais ou sobre a força de trabalho, como um todo, ainda estão para ser mensurados.

Em relação à implantação de um governo eletrônico, também cabe ressaltar que o website oficial do governo brasileiro ${ }^{6}$ possui informações institucionais sobre a estrutura e as ações de governo e oferece links para a prestação eletrônica de 101 serviços de utilidade pública, mas o seu principal objetivo é o de criar um canal de comunicação com a sociedade por meio da facilidade do Fale Conosco, que é administrado pela Secretaria de Comunicação de Governo da Presidência da República.

Contudo, há um website, conhecido como o portal de serviços da rede governo, ${ }^{7}$ mantido pela Secretaria de Logística e Tecnologia da Informação, que também é dedicado à prestação de serviços e à divulgação de informações públicas.

Este "portal é a entrada virtual para todas as páginas oficiais brasileiras disponibilizadas na Internet por meio de links diretos a mais de 700 páginas de serviços e 4.000 sites com informações governamentais". ${ }^{8}$

\section{Canadá}

Em 1996, o Ministério de Suprimento e Serviços do Canadá publicou o documento intitulado Construindo a Sociedade da Informação: Movendo o Canadá em Direção ao Século XXI, ${ }^{9}$ em que são apresentadas as políticas e iniciativas a serem adotadas para facilitar a transição rumo a uma sociedade da informação e a uma economia do conhecimento. Assim, são definidas quatro grandes linhas de ação:

a) o desenvolvimento de uma supervia da informação;

b) a promoção e incremento do conteúdo canadense;

c) a obtenção de benefícios econômicos e sociais para todos os canadenses; e

d) um governo acessível, responsivo e com melhor qualidade nos serviços prestados.

Este documento não identifica especificamente os impactos na estrutura organizacional e na força de trabalho da administração pública, mas genericamente e também pelo fato de no Canadá existir um Ministério do Desenvolvimento dos Recursos Humanos, existe o compromisso de que um dos seus objetivos estratégicos é o da criação de empregos em função da inovação e dos investimentos esperados.

Também, por ser país produtor de conhecimento e, dentro da segunda linha de ação de produção de conteúdo - há explicitação de estratégia de expansão de oportunidades e da criação de empregos. 
Em relação à terceira linha de ação, relativa à aquisição de benefícios advindos das novas configurações produtivas, há compromisso do governo em identificar os impactos sobre o emprego e em assegurar que os padrões de trabalho dos trabalhadores sejam protegidos, além do que são empreendidos esforços do governo federal no sentido de promover a cooperação entre as províncias, os territórios, os empregadores e outros interessados, no sentido de adotar uma cultura de educação continuada, considerada como parte integrante da evolução para uma Sociedade da Informação.

Em abril de 1997, o Ministério do Trabalho do Canadá publicou o documento "O Impacto da Supervia da Informação sobre o Ambiente de Trabalho" 10 , resultado dos debates realizados durante o Fórum Nacional sobre a supervia da informação e aspectos relacionados ao ambiente de trabalho.

Neste documento não é dada tanta ênfase à tecnologia em si, mas à análise das conseqüências das TIC sobre o trabalho, particularmente sobre o emprego, sobre as novas formas de organização do trabalho e sobre a necessidade de serem empreendidas ações no sentido de "assegurar proteção ao trabalhador" (pág. 1).

Como resultados deste Fórum Nacional, que contou com a participação de representantes das empresas e dos trabalhadores canadenses, $o$ governo pode consolidar as perspectivas, as considerações e as sugestões apresentadas, pelas duas representações, sobre os seguintes temas:

a) formas não padronizadas de trabalho:

- jornada reduzida de trabalho;

- trabalho temporário ou sub-contratado; e

- teletrabalho.

b) horas de trabalho e distribuição do horário de trabalho;

c) trabalho autônomo;

d) distribuição da renda e das oportunidades de trabalho; e

e) educação, treinamento e desenvolvimento de capacidades.

Como conclusão são destacadas a necessidade de uma ação inovadora da sociedade canadense que combine os desafios de regulamentar e, simultaneamente, de dar maior flexibilidade e proteção ao trabalho, assim como de priorizar ações no sentido de promover as novas habilidades e capacidades laborais dentro de um processo de educação e de aprendizagem contínua.

A partir destas definições estratégicas, o governo canadense estabeleceu diversas parcerias com a iniciativa privada e com organizações não-governamentais no sentido de criar:

a) o CanWorkNet, ${ }^{11}$ um diretório nacional coordenado pelo Ministério do Desenvolvimento dos Recursos Humanos que possui uma base de dados com os endereços eletrônicos de documentos e organizações relacionadas 
aos temas: emprego, desenvolvimento de carreiras, mercado, local de trabalho etc.;

b) a SchoolNet, um projeto coordenado pelo Ministério da Indústria que pretende interligar as 16.500 escolas canadenses, de forma a promover o intercâmbio de experiências de aprendizagem;

c) o Office of Learning Technologies, subordinado ao Ministério do Desenvolvimento dos Recursos Humanos, com o intuito de promover o efetivo uso das tecnologias de aprendizagem e de expandir novas oportunidades de aprendizado inovativas; e

d) o TeleLearning Network of Centres of Excellence, da Universidade de Fraser, em que pesquisadores de padrão internacional buscam, de forma colaborativa, desenvolver abordagens de ensino adequadas às novas tecnologias e ao estabelecimento de uma sociedade do conhecimento.

O governo canadense é reconhecido como um dos grandes inovadores na prestação de serviços via Internet, não só por disponibilizar informações e serviços de forma integrada por meio de um portal ${ }^{12}$, mas por possibilitar o acesso a estas facilidades tanto em inglês como em francês e também por disponibilizá-los tanto por áreas temáticas (tributos, cultura, saúde, justiça etc.), como por grupos de interesse (povos indígenas, crianças, jovens, aposentados, imigrantes, portadores de deficiências e canadenses vivendo no exterior).

\section{Cingapura}

Conforme relatório da consultoria Accenture $^{13}$ (de abril deste ano), intitulado Liderança em Governo Eletrônico, ${ }^{14}$ entre 22 governos que buscam o aperfeiçoamento das suas soluções de governo eletrônico, Cingapura ocupa o segundo lugar (logo abaixo do Canadá) em uma categoria que é classificada como "maturidade em e-gov" — um conceito que engloba definições como tipo, nível e modo com que os serviços de divulgação de informações, de interação e de transações eletrônicas são prestados por estes mesmos governos.

Cingapura apresenta-se como uma liderança inovadora ao buscar transformar-se em uma "ilha inteligente" e em referência internacional na cons trução de uma nova economia digital e na prestação de serviços de governo eletrônico, sendo que para isso, implantou o que é conhecido como Singapore One, uma rede de comunicações nacional onde estão interligados todos os prédios do governo, as empresas, as escolas e as residências.

Para tanto, tem realizado investimentos, tanto em infra-estrutura de informação e de comunicações, como no processo de repensar novas formas de governança, que fez com que aumentasse a eficiência de seus processos internos e, simultaneamente, elevasse a qualidade dos serviços cada vez mais centrados na satisfação das empresas e dos cidadãos. 
Em setembro de 2000, foi publicado um Plano de Ação para o Governo Eletrônico, ${ }^{15}$ em que é estabelecido um orçamento de US\$ 1,5 bilhões para investimentos em TIC (para os próximos três anos) e também são definidas cinco estratégias e seis iniciativas com o objetivo de dar suporte à sua estratégia de firmar-se como líder em uma economia global, cada vez mais embasada na criação e na gestão do conhecimento:

a) Estratégias para o governo eletrônico:

- governo como destaque na prestação de serviços de forma eletrônica;

- busca contínua de vantagens em relação ao uso das TIC e aos novos modelos de negócio/gestão;

- inovações baseadas no uso de novas tecnologias e no desenvolvimento de novas capacidades de desenvolvimento e de aprendizagem;

- setor público pró-ativo e responsivo às novas tendências tecnológicas, à definição de políticas públicas, à melhoria na prestação de serviços e à simplificação de regulamentações; e

- desenvolvimento de uma melhor compreensão dos impactos das novas tecnologias e de lideranças ativas que promovam inovações nos vários aspectos da governança.

b) Iniciativas para implementar a sua visão de governo eletrônico:

- um ambiente de trabalho baseado no conhecimento, onde todos os servidores sejam capacitados em TIC, de forma a aprimorar os processos internos, a prestação de serviços e o trabalho em equipe;

- prestação eletrônica de todos os serviços públicos passíveis de assim serem implementados;

- experimentação tecnológica, como forma de proporcionar rápida adaptação às novas tendências e reduzir gastos com grandes investimentos;

- aumento da eficiência operacional, pelo uso de uma moderna infraestrutura de hardware e software por parte de todos os servidores públicos;

- uso de uma infra-estrutura de comunicações robusta, capaz de atender a elevados requisitos de escalabilidade e de conectividade; e

- programas de educação em TIC, de modo a promover melhorias nos processos de trabalho e na prestação de serviços.

Com o objetivo de dar consistência às suas estratégias de desenvolvimento, o governo de Cingapura criou uma entidade pública denominada (Infocomm Development Authority of Singapore - IDA) ${ }^{16}$ responsável pelo planejamento, pela coordenação e pela regulamentação das políticas e de uma estrutura produtiva que dêem suporte ao estabelecimento, não apenas de um governo eletrônico, mas de uma indústria e de uma sociedade que possuam uma posição de destaque no cenário internacional.

Dentre as suas atribuições de definição de políticas e de regulamentação do desenvolvimento de novas tecnologias, de inovadoras formas de negócios eletrônicos e de inserção internacional, o IDA propiciou a 
criação de um grupo de trabalho voltado para o planejamento de sistemas governamentais (Government Systems Group - GSG), uma divisão dedicada ao desenvolvimento da força de trabalho, tanto pública como privada (Manpower Development Division - MDD) e um programa de preparação do servidor público para enfrentar os desafios do século XXI (Public Service for the $21^{\text {st }}$ Century - PS21). ${ }^{17}$

Como principais ações do primeiro grupo de trabalho criado pela $I D A$, o grupo de planejamento de sistemas governamentais ( $G S G)$ temos:

a) a criação do portal do governo de Cingapura $^{18}$ (em 1995);

b) o desenvolvimento de um centro virtual de prestação de serviços aos cidadãos (o e-Citizen Centre) ${ }^{19}$ sendo que este último está organizado, não pelas estruturas de governo, mas por life events, ${ }^{20} \mathrm{e}$

c) a criação de um portal de vendas eletrônico (Government Shopfront $)^{21}$ para todas as publicações e vídeos do Ministério do Desenvolvimento da Comunidade, além de todas as publicações do Ministério de Estatísticas.

Já em relação ao desenvolvimento do capital humano, foi criado um grupo de desenvolvimento da força de trabalho $(M D D)$, também vinculado à $I D A$, cujo objetivo é o de promover a formação e o emprego de recursos capacitados em TIC, de forma a assegurar que existam os fundamentos necessários à atuação competitiva do país em âmbito internacional.

Para atingir estes objetivos, foram priorizadas iniciativas em três áreas de atuação:

a) treinamento;

b) programas de certificação e de reconhecimento profissional; e

c) e-Learning.

As ações de treinamento estão voltadas, tanto para os profissionais de tecnologia, como para os trabalhadores considerados usuários finais destas facilidades. Neste sentido, foram estabelecidas algumas parcerias com empresas privadas, com o intuito de implantar programas específicos de:

a) requalificação profissional (como o Skills Redevelopment Program - $S R P$ ), em que os trabalhadores adquirem habilidades nas várias áreas da informática relacionadas à automação de escritório;

b) aperfeiçoamento de profissionais das TIC (por meio do Critical IT Resource Program - CITREP);

c) conversão de trabalhadores de outros ramos em profissionais das TIC (por meio do Strategic Manpower Conversion Program - SMCP);

d) capacitação e treinamento de especialistas em comércio ele trônico (Electronic Commerce Specialist Manpower Program - ECSMP) e em TIC (Infocomm Specialist Manpower Program - ISMP); e

e) programas de capacitação e treinamento de trabalhadores mais velhos e de novos contratados. 
Também foram realizadas ações no sentido de incentivar amplos processos de certificação e de reconhecimento profissional para as áreas de conhecimento consideradas críticas para o desenvolvimento de habilidades identificadas como necessárias, tanto para o aperfeiçoamento do serviço público, como da indústria.

Estes programas de certificação (por exemplo, o PC Driving Test e o Certified IT Project Management - CITPM) estão inseridos em um projeto nacional de elevação da qualidade da mão-de-obra e de incentivo à aprendizagem contínua, sendo que a adoção de padrões internacionais de certificação faz com que exista não só um amplo reconhecimento nacional, mas internacional das competências profissionais adquiridas por meio destes processos.

A terceira vertente de ações voltadas ao desenvolvimento do capital humano - e-Learning - envolve o uso do ambiente Internet como forma de disseminar cursos virtuais e sistemas de gestão do aprendizado nas organizações públicas e privadas que compõem os setores-chave da economia.

Para tanto, foram definidos três programas governamentais com vistas à promoção das ações de $e$-Learning:

a) o estabelecimento de infra-estrutura e adoção de padrões técnicos;

b) o desenvolvimento de conteúdo;

c) o incentivo à cooperação entre criadores e usuários e ao estabelecimento de redes de compartilhamento do conhecimento.

A abordagem inovadora do e-Learning proporciona substanciais ganhos operacionais, mas fundamentalmente também permite o acesso à informação e ao conhecimento, em qualquer lugar e em qualquer momento, que venham a promover a melhoria da produtividade e do desempenho de qualquer profissional, governo ou organização.

Já o programa de modernização do serviço público em Cingapura, denominado PS 21, busca criar condições que assegurem o bem-estar dos servidores, assim como a reestruturação organizacional e a qualidade dos serviços prestados, pela valorização da criatividade, da inovação e do aprendizado contínuo.

Para tanto, foram criados:

a) um programa de Desafio Empresarial (The Enterprise Challenge - TEC), com orçamento previsto de US\$ 10 milhões, para patrocinar a renovação e a geração de novos valores no serviço público, assim como melhorar a qualidade dos serviços prestados; e

b) um programa de Gestão para a Excelência (Managing for Excellence - MFE), voltado à motivação dos servidores, à consolidação de uma cultura organizacional orientada ao cidadão e à inovação na gestão de recursos públicos. 
Finalmente, com o intuito de consolidar uma política de excelência

por meio de um programa de empreendedorismo e de aprendizagem contínua (Excellence through Continuous Enterprise and Learning - ExCEL), também foi desenvolvido um website denominado Learning Organization In Action, ${ }^{22}$ que pretende ser uma referência na divulgação de documentos, bibliografia, ferramentas, práticas e dicas sobre o tema, para todos os servidores públicos.

\section{Reino Unido}

O Livro Branco da Modernização do Governo ${ }^{23}$ britânico foi publicado em março de 1999 e ressalta as características de uma nova realidade em que o governo deve ser capaz de adaptar-se continuamente a reestruturações sociais, políticas e econômicas, aos impactos das TIC, a buscar novas formas de inter-relação com os cidadãos e com o mercado e a promover a aprendizagem contínua de seus servidores.

Assim, este documento apresenta um programa de mudanças em que a modernização do serviço público, orientada para o atendimento ao cidadão e a resultados, é peça fundamental na melhoria na forma como o governo:

a) elabora as suas políticas;

b) provê serviços de interesse da sociedade;

c) avalia a qualidade dos serviços prestados;

d) utiliza as novas tecnologias; e

e) valoriza o serviço público.

Destes cinco pressupostos surgiu a recomendação de que fosse desenvolvida uma estratégia de utilização das TIC que resultou em um documento intitulado "Governo Eletrônico - Uma estrutura estratégica para os serviços públicos na era da informação", ${ }^{24}$ publicado em abril de 2000.

Neste documento não estão determinadas soluções técnicas ou tecnológicas, mas é feito um direcionamento em que espera-se que o serviço público deverá adotar novos modelos de gestão a partir do desenvolvimento do potencial de mudança das novas tecnologias, basicamente por meio de soluções de e-business, em que o governo poderá prestar informações e serviços à sociedade (e-gov), bem como realizar aquisições e estabelecer transações eletrônicas (e-procurement) de forma a melhor atender as necessidades/demandas dos cidadãos e das empresas.

Dentre os benefícios destas orientações são destacadas a redução de custos, a maior eficiência, o melhor compartilhamento de informações e de bases de conhecimento, uma maior integração de serviços e de experiências, a possibilidade de formas de trabalho mais flexíveis e a oportunidade de desenvolvimento de habilidades e de capacitação por parte dos servidores públicos. 
Um dos desafios deste novo ambiente de trabalho, no setor público, seria o de gerenciar o processo de redirecionamento e de requalificação da mão-de-obra, a ser liberada das atividades meio para o atendimento às atividades finalísticas das organizações públicas.

Neste sentido, o governo do Reino Unido demonstra uma grande preocupação em relação ao desenvolvimento e à capacitação dos servidores, que deverão enfrentar demandas relativas às novas formas de prestação de serviço e à aquisição de novos conhecimentos e de novas habilidades.

Estas habilidades, identificadas como necessárias à adequada implementação de um governo eletrônico são, inicialmente, subdivididas em quatro áreas de interesse e, posteriormente, representadas graficamente em um diagrama (e-gov skills map) com sete blocos de habilidades. Estes dados e classificações podem ser aglutinados e categorizadas em nove grandes grupos de habilidades, que foram identificadas a partir de uma visão orientada a mudanças, mas preocupada com as pessoas:

a) liderança e definição de políticas públicas;

b) gerência de projetos e de mudanças;

c) gestão de relacionamento com fornecedores;

d) gestão de compras e de transações eletrônicas;

e) desenvolvimento de sistemas de negócio;

f) profissionalismo em tecnologias da informação;

g) profissionalismo em ciência da informação;

h) uso de novas ferramentas para melhoria da qualidade e da eficácia dos serviços; e

i) outras especialidades.

Em março de 2001, a Organização do Governo Central para o Treinamento Nacional (Central Government National Training Organisation - CGNTO) publicou um plano de desenvolvimento para a força de trabalho, alocada ao serviço público civil, intitulado Desenvolvendo Habilidades para o Século XXI, ${ }^{25}$ em que são identificadas as necessidades e as características das novas habilidades profissionais a serem validadas e implementadas pelos gestores de recursos humanos.

Aliada às necessidades de empregabilidade, de aprendizagem contínua, de maior flexibilidade e de elevada qualificação do capital humano, a modernização do serviço público deve buscar o alcance de metas e de resultados, a responsabilização pessoal, o reconhecimento de talentos, a valorização da diversidade e a integração de equipes e de organizações.

Com estes objetivos e, primordialmente, para que o governo possa transformar-se em uma organização de aprendizagem (learning organisation) são identificadas algumas áreas onde a falta de capacitação profissional gera os maiores impactos, a saber: 
a) na prestação de serviços;

b) na definição e no atendimento a padrões de qualidade;

c) nos processos de mudanças organizacionais; $\mathrm{e}$

d) na mudança tecnológica.

Assim, são priorizadas 15 áreas de atuação e direcionamento de investimentos para promover o treinamento, a educação e o desenvolvimento de habilidades da força de trabalho civil do governo britânico:
a) básicas;
b) chave e/ou genéricas;
c) tecnologias da informação e de comunicação;
d) diversidade;
e) liderança;
f) gerência de desempenho;
g) gestão de pessoas;
h) gerência de negócios;
i) gerência de projetos;
j) prestação de serviços aos cidadãos;
k) habilidades políticas;
1) gerência de riscos;
m) parcerias;
n) visão da União Européia; e
o) outras especialidades.

Umas das inovações, que transformaram o Reino Unido em referência internacional na prestação de serviços de forma eletrônica a seus cidadãos, é a de que no portal de serviços e de informações do governo britânico ${ }^{26}$ há uma tela inicial que permite a escolha do país (Inglaterra, Escócia, País de Gales e Irlanda do Norte) e do idioma (inglês ou gaélico), com opção para a armazenagem destas configurações, de modo a poderem ser restauradas em visitas posteriores a este website.

Além destas adequações ao perfil do cidadão, este portal de serviços, assim como o portal do governo de Cingapura, também está organizado por life episodes ${ }^{27}$ e não por estruturas governamentais.

\section{Estudo de Caso 1 - Secretaria da Receita Federal / Brasil}

A Secretaria da Receita Federal (SRF), vinculada ao Ministério da Fazenda, é a entidade responsável pela administração dos tributos internos e aduaneiros no Brasil e exerce as atividades de arrecadação, fiscalização, tributação e de apoio tecnológico, além da promoção de atividades de integração com o contribuinte. 
Desde 1995, vem adotando ações de modernização e de melhoria da qualidade do atendimento ao contribuinte, tendo como pressupostos básicos o estabelecimento de formas de atendimento integradas, eficientes e conclusivas, organizadas em função das características das atividades e com funcionamento em locais adequados e de fácil acesso.

Com a integração e a reestruturação das diversas áreas técnicas foi montada uma estrutura de atendimento composta por postos de informações, formas de atendimento expresso e personalizado, os balcões de expedições, os plantões fiscais e o aperfeiçoamento dos atendimentos telefônicos.

Também foram realizados treinamentos voltados para a área comportamental, enfatizando o relacionamento interpessoal, a integração e o fortalecimento das equipes.

Com a conseqüiente valorização da atividade de atendimento, observou-se uma maior satisfação dos próprios atendentes, havendo incrementos nos níveis de produtividade e uma maior satisfação do contribuinte em relação aos procedimentos técnicos da Receita Federal.

Estas ações estavam associadas a um concomitante processo de modernização tecnológica onde o ambiente Internet foi o instrumentochave para que a SRF se transformasse em um referencial de qualidade e eficiência na prestação de serviços públicos.

As principais ações relacionadas ao estabelecimento de uma e-Receita ou Receita Virtual foram:

a) a implantação do Centro de Atendimento ao Contribuinte (CAC);

b) o desenvolvimento do Projeto ReceitaNet, ${ }^{28}$ com:

- a divulgação de orientações para o preenchimento das declarações de renda no website da SRF;

- o oferecimento de programas (download) gratuitos para o preenchimento das declarações de renda via Internet,

- a entrega de declarações de renda e emissão do comprovante de entrega pela Internet,

c) a substituição da sistemática de arquivamento e consulta a declarações em papel por arquivamento em meio eletrônico;

d) o atendimento ao contribuinte por correio eletrônico (sendo que de 1996 a 1998 foram feitas 64.951 consultas via e-mail e o padrão de atendimento é o de respostas enviadas em até sete dias úteis);

e) a emissão de certidão negativa de débitos de tributos e contribuições federais, via Internet;

f) o oferecimento de programa (download) gratuito para a realização de cálculos de acréscimos legais, com a geração automática do Documento de Arrecadação Federal, via Internet — Sistema de Cálculos de Acréscimos Legais (SICALC);

g) a consulta à situação cadastral e às restituições de tributos;

h) a utilização de ferramentas de trabalho informatizadas para a aperfeiçoar os processos de comunicação (e-mail), discussão (e-groups 
e message boards), trabalho cooperativo (workgroups) e homologação

de sistemas e serviços; e

i) a implantação de sistema eletrônico de coleta de dados e gerenciamento de todas as etapas do atendimento realizado no Sistema Nacional de Apoio ao Gerenciamento do Atendimento (SAGA).

Estes novos processos foram reconhecidos, alguns internacionalmente - como é o caso do ReceitaNet - , como inovações que resultaram em uma melhor organização do ambiente de trabalho, na maior capacidade de planejamento gerencial, na redução no tempo de espera e de atendimento ao contribuinte e em uma maior conclusividade dos atendimentos, além de influenciar positivamente nos níveis de motivação e de produtividade dos servidores envolvidos.

\section{Estudo de Caso 2 - Instituto Nacional do Seguro Social/Brasil}

O Instituto Nacional do Seguro Social (INSS), vinculado ao Ministério da Previdência e da Assistência Social tem por finalidade promover a arrecadação, a fiscalização e a cobrança das contribuições sociais, gerir os recursos do Fundo de Previdência e Assistência Social e conceder e manter os benefícios previdenciários no Brasil.

Em 1998 foi estabelecido o Programa de Melhoria no Atendimento na Previdência Social com o objetivo de promover uma maior agilidade na prestação de serviços e na concessão de benefícios, uma maior comodidade aos usuários e a ampliação do controle social. Para tanto, foram estabelecidas as diretrizes de utilização intensiva de novas tecnologias, de revisão dos processos de trabalho, de garantia de acesso às informações da Previdência Social e do estabelecimento de um canal de comunicação direto com a sociedade.

Neste sentido, foi planejado um processo de reestruturação organizacional baseado no fortalecimento de formas de administração colegiada e de gestão empreendedora, no estabelecimento de práticas de descentralização decisória, na valorização dos servidores, na adoção de uma sistemática de seleção interna de gerentes executivos e na implantação de uma área de controladoria com duas coordenações: uma de gerenciamento da qualidade do atendimento e outra de aferição de resultados.

A estas iniciativas de modernização organizacional, somaram-se um conjunto de ações voltadas para a melhoria do atendimento, em que o uso intensivo das novas tecnologias da informação e de comunicação proporcionaram o desenvolvimento de formas de atuação inovadoras, com destaque para: 
a) a implantação de centrais telefônicas de atendimento gratuito aos usuários, com atendimento inclusive aos sábados (PREVFone);

b) o desenvolvimento do Projeto PREVNet, ${ }^{29}$ em que 54 tipos de serviços e benefícios já estão disponíveis via Internet (com destaque para as facilidades de alteração de endereço, o download de formulários necessários à concessão de benefícios, o requerimento de benefícios, a simulação da contagem de tempo de contribuição, o acompanhamento do andamento de processos, a consulta a extrato de pagamentos, a emissão de certidão negativa de débitos, a consulta aos dados cadastrais das empresas e a verificação de regularidades junto ao fisco previdenciário);

c) o oferecimento de programa (download) gratuito que permite o cadastramento das informações pertinentes à pré-habilitação de um benefício previdenciário e a impressão dos formulários necessários para o posterior requerimento do benefício (Disquete Previdência);

d) o cadastramento de contribuintes individuais, a alteração de endereço, a consulta a informações cadastrais, o fornecimento de informações sobre as contribuições individuais e a consulta a vínculos empregatícios e remunerações dos trabalhadores empregados (PREVCidadão);

e) a modernização dos postos/agências de atendimento aos usuários, com inovações tecnológicas e gerenciais que resultaram no estabelecimento de padrões de atendimento, em uma melhor organização do ambiente de trabalho, na redução do tempo de espera e de atendimento aos usuários, além de proporcionar a elevação dos níveis de motivação e de produtividade dos servidores envolvidos

f) a promoção de ações itinerantes de atendimento integrado, oferecido por intermédio de 69 unidades móveis e quatro barcos, para servir às populações carentes e/ou com dificuldades de transporte, visando informar e orientar as comunidades visitadas sobre seus direitos e deveres previdenciários, sociais e trabalhistas (PREVMóvel);

g) a instalação de quiosques de auto-atendimento nas novas agências e em outros espaços públicos, como associações, sindicatos etc., de forma a permitir a consulta a informações e o acesso aos serviços para aqueles usuários que não necessitam de atendimento personalizado ou não possuem facilidades de acesso à Internet.

Este processo de modernização e de aprimoramento dos serviços prestados foi precedido de um estudo dos perfis e das competências necessárias à ocupação dos postos de trabalho nas novas agências do INSS — atendentes de orientação e informação, atendentes para o serviço especializado e monitores de atendimento.

Para cada um dos grupos de profissionais envolvidos foi elaborado um programa de capacitação próprio, tendo sido ministrado treinamento específico e implantado o programa de Treinamento no Local de Trabalho (TLT) - estações de trabalho — , que utiliza o ambiente Intranet como 
forma de garantir a atualização dos conteúdos e o aperfeiçoamento permanente dos servidores.

\section{Reflexões e questionamentos}

Deixando de lado, temporariamente, as questões relativas a custos, infra-estrutura, segurança, interligação de redes e sistemas e certificação digital, quem não gostaria de acessar um escritório do governo sem precisar perder tempo com deslocamentos ou enfrentando filas, servidores desmotivados, ambientes insalubres ou correr o risco de metamorfosear-se em um personagem kafkiano, sob a irracionalidade e o arbítrio da burocracia?

Também deixando de lado, temporariamente, as questões relativas à alfabetização digital, treinamento e requalificação profissional, opções tecnológicas, privacidade e exclusão digital, quem não gostaria de ser informado ou ter um serviço público prestado, em qualquer horário ou lugar do planeta, pela Laura $\mathrm{Croft}^{30}$ ou por qualquer outro "avatar", a ser previamente configurado, além de ser atendido pelo nome e ter a liberdade de escolher o sotaque, a trilha sonora e outros skins?

Pois os administradores e os servidores públicos que aceitaram o desafio de enfrentar as antigas estruturas burocráticas, o departamentalismo e o corporativismo e buscam implantar políticas e metodologias que viabilizem uma administração moderna voltada aos interesses dos cidadãos encontraram uma oportunidade para reavivar as suas convicções e reforçar as suas posições - a visão de uma Era da Informação, em que todos anseiam pela "revolução" que pode advir com o uso intensivo das novas TIC.

Este novo paradigma, em que os governos funcionam 24 horas por dia, divulgando informações e prestando serviços de maneira mais rápida, com menores custos e melhor qualidade, promovendo um controle social mais eficiente, incrementando o compartilhamento de informações e a integração de serviços e adotando o uso de transações eletrônicas de forma abrangente, ainda está para ser construído e, como os sociólogos costumam ensinar, atualmente trata-se de uma utopia ou um ideal a ser atingido.

Também acredita-se que as novas TIC impulsionem a adoção de novos modelos de gestão e de negócio, que nas organizações privadas já estão, de certa forma, consolidadas e vão, desde a simples reengenharia digital de processos, passando pelo emprego de técnicas de segmentação de mercado, pela criação de redes de valor e pelo gerenciamento do relacionamento com clientes, até ao uso de ferramentas de $e$-Learning e de sistemas de gestão do conhecimento que promovem a inovação, a melhoria de processos e a criação de novos produtos.

Estes novos modelos de negócio para as organizações públicas, que buscam restringir as ações de mera transformação da burocracia 
existente a uma burocracia digital (e-burocracia) e que devem substituir os antiquados modelos de administração por estruturas de gestão mais dinâmicas e flexíveis, estão baseados em dois grandes eixos: ${ }^{31}$

a) o de integração horizontal, que possibilita economias de escala e uma maior visão das necessidades dos cidadãos; e

b) o de integração vertical, que permite a criação de redes de valor entre as áreas e entre as organizações envolvidas na prestação de serviços públicos.

A partir destes pressupostos é que devem ser pesquisados os impactos das TIC nas estruturas, nas formas de gestão, no adequado perfil do capital humano e no desempenho das organizações públicas, porém, a escassa literatura sobre o assunto apenas demonstra a existência de um "paradoxo empírico" 32 em relação às mudanças que podem ocorrer nas estruturas $^{33}$ e no desempenho ${ }^{34}$ das organizações públicas.

Desta forma, como demonstrado nos estudos de caso, e possivelmente, de maneira distinta das organizações privadas, não podemos imputar um determinismo tecnológico a tais processos de mudança, pois as peculiaridades das estruturas organizacionais do serviço público, as influências políticas-institucionais e os impactos do contexto sócio-econômico também são fatores decisivos que devem ser considerados em uma análise das transformações por que passam as estruturas das organizações públicas.

Porém, dentro das possíveis formas de planejamento, de coordenação e de intervenção dos agentes públicos, assim como do grau de efetividade das políticas adotadas, há uma clara diferenciação entre as estratégias empreendidas por cada um dos quatro países analisados.

Tanto o Canadá (de forma extremamente participativa) como Cingapura apresentam detalhados programas de promoção de seus governos eletrônicos, que por estarem atrelados às suas estratégias de desenvolvimento nacional e industrial, fazem com que já tenham concretizado muitas das ações de estabelecimento de infra-estrutura e de universalização do acesso, e aqui vale ressaltar, por meio de parcerias com empresas e com outros níveis de governo.

Estes dois países, também, demonstram possuir um maior direcionamento em relação ao desenvolvimento de conteúdo e um efetivo planejamento e uma elaborada estruturação para enfrentar as questões relacionadas à empregabilidade e às políticas de capacitação e de requalificação, não só dos servidores públicos, mas da força de trabalho nacional.

O Reino Unido, que tem como uma de suas estratégias nacionais transformar-se em referência mundial em termos de $e$-commerce, apresenta diversas inovações em relação às formas de prestação de serviços e de inter-relação com os seus cidadãos, mas tem como destaque a realização de um complexo trabalho de identificação das áreas onde a falta de capacitação profissional gera os maiores impactos e de priorização das 
áreas de atuação e de direcionamento de investimentos para promover o treinamento, a educação e o desenvolvimento das competências de seus servidores civis.

O governo britânico, de maneira exemplar, disponibiliza na Internet um documento (e-bussiness Skills Assessment Toolkit) ${ }^{35}$ com a metodologia e as ferramentas empregadas na identificação dos gaps existentes entre as habilidades necessárias e a real situação da força de trabalho, de forma a assegurar que as estratégias de $e$-business adotadas pelas diversas organizações públicas sejam adequadamente implementadas e que as necessidades de capacitação e de treinamento estejam identificadas, validadas e adequadas às estratégias de consolidação do seu governo eletrônico.

No Brasil, que apresenta um enorme esforço de estruturação de seu governo eletrônico, ainda são identificadas necessidades básicas para a implantação da infra-estrutura, de uma padronização e de uma integração de redes e sistemas, além de serem relevantes as questões relacionadas à alfabetização e à exclusão digital, que fazem com que as ações relativas à capacitação e à realocação de servidores não tenha sido abordada com tanta ênfase.

Nestes casos, é comum que sejam propostas de reavaliação dos apoios políticos e da adequação das equipes e dos recursos financeiros, além do que é decisivo o entendimento de que as tecnologias devem ser vistas como simples ferramentas que não podem, e nem devem, substituir a definição de políticas, das formas de intervenção ou das "estratégias para a promoção da Sociedade da Informação", 36 assim como a definição e elaboração das políticas de recrutamento, gestão, remuneração e capacitação de recursos humanos.

Paradoxalmente, as duas organizações públicas brasileiras analisadas (SRF e INSS), apesar de terem adotado ações de modernização e de melhoria da qualidade do atendimento aos cidadãos baseadas nas tecnologias da informação, apresentaram características bastante distintas em relação aos impactos destas modernas tecnologias sobre as suas estruturas e sobre a administração do seu capital humano.

\section{Conclusões}

As demandas das chamadas Eras da Informação e do Conhecimento impuseram, e estão gestando, constantemente, novos desafios à forma com que as organizações estruturam-se e gerenciam recursos, clientes, fornecedores e tecnologias, chegando a ser considerado "comum", hodiernamente, o fato de governos, empresas e cidadãos transacionarem com/como as chamadas organizações virtuais e ser taxado de "incomum" o fato de indivíduos ou parcelas da população serem considerados analfabetos tecnológicos ou excluídos digitais. 
Estas novas tecnologias que tanto permitem a criação de inusitadas e produtivas formas e ambientes de trabalho, por outro lado, também fazem com que, de forma cada vez mais dinâmica, sejam demandadas distintas habilidades e competências e imponham permanentes formas de aprendizado.

As novas formas de organização do trabalho, capazes de melhor atender às necessidades de realização de múltiplas tarefas e de melhor adaptarem-se às mudanças sócio-econômicas e organizacionais podem ser identificadas em inúmeros "casos de sucesso" pelo mundo afora, mas ainda são muito díspares para definirem um modelo ideal a ser seguido, não são maioria e também não apresentam antídotos conclusivos frente às turbulências dos ciclos econômicos ou às flutuações dos mercados internacionais.

Contudo, mesmo não existindo um modelo único, mas diversos caminhos a serem criados, já podem ser identificadas algumas tendências nas organizações que são consideradas paradigmas deste novo modelo de organização do trabalho:

a) as estruturas são menos hierarquizadas, mais flexíveis e embasadas em redes de relacionamento, de conhecimento e de valor;

b) os ambientes de trabalho são informatizados, interligados e baseados no ambiente Internet, distribuídos geograficamente e estruturados de forma a incentivar a educação e o aprendizado contínuo;

c) os horários de trabalho são mais flexíveis e há a utilização de teletrabalho para determinadas tarefas, com consequientes inovações na forma de gerenciamento de pessoal e de desempenho;

d) são implantadas sistemáticas de desk-share nas áreas voltadas para o relacionamento com os clientes;

e) é incentivado o uso das novas tecnologias para a adoção de práticas de gestão do conhecimento e de $e$-Learning;

f) os empregados devem ser mais generalistas e possuir elevados potenciais de aprendizagem, características mais adequadas à realização de múltiplas tarefas e às constantes mudanças organizacionais e do mercado;

g) há uma maior ênfase em novas formas de contratação e de recrutamento, baseadas no potencial de aprendizado, na adaptabilidade e nas capacidades de comunicação e relacionamento ao invés de privilegiar a formação e o currículo profissional;

h) as organizações buscam ser mais "flexíveis", promovendo contínuas reestruturações organizacionais e o permanente aprendizado de seus colaboradores;

i) há um direcionamento para a substituição da força de trabalho permanente por temporária ou, mesmo, por uma força de "trabalho situacional"; 37 
j) existe um incremento dos processos de requalificação, de melhoria da empregabilidade e de recolocação profissional;

k) há um maior incentivo ao estabelecimento de parcerias voltadas ao aperfeiçoamento do desempenho, do aprendizado e do compartilhamento de recursos; e

1) os sistemas de remuneração buscam ser cada vez mais capazes de incentivar e atender práticas de alto desempenho profissional.

Nas organizações públicas, em função de suas peculiaridades, também são indicadas tendências no sentido de:

a) adotar legislações que permitam formas mais flexíveis e menos regulamentadas de emprego público;

b) dar maior flexibilidade gerencial e promover uma maior descentralização da gestão da força de trabalho (contratação, desligamentos e promoções);

c) promover um maior compromisso com o desempenho, com a obtenção de resultados e com a transparência e a prestação de contas;

d) assegurar elevados padrões de conduta, de comportamento e de ética profissional;

e) oportunizar melhores oportunidades a minorias a portadores de deficiências;

f) adotar formas de remuneração associadas ao desempenho; e

g) capacitar gerentes para motivar, dirigir e avaliar equipes, liderar em ambientes de mudança e adotar postura ativa em relação a parcerias e novos negócios.

Isto posto, entendo que estas tendências devam ser utilizadas pelas administrações públicas como subsídios para uma discussão que busque a construção de uma Sociedade da Informação, de forma articulada com todos os parceiros sociais e que tenha como objetivo a adoção de modernas formas de governança que contemplem novos formatos de organização do trabalho que sejam produtivos, voltadas ao aprendizado e participativos.

Mas, principalmente, que os policy makers envolvidos estejam conscientes das condições sociais, culturais, políticas e macroeconômicas de suas sociedades e, ao exercitarem suas funções de elaboradores de políticas públicas e de legisladores, que avaliem o potencial de suas ações e que possam estabelecer uma adequada relação entre os níveis de emprego e da atividade econômica, entre o nível dos gastos públicos e o seu efeito multiplicador, assim como vislumbrem um legítimo equilíbrio entre os requisitos de segurança e de flexibilidade do trabalho. 
1 Sob a óptica da teoria econômica, existem três aspectos em que o progresso técnico e a inovação podem ser contextualizados. Em primeiro lugar, na teoria dos ciclos econômicos, sempre que o progresso técnico (que reduz custos e aumenta a produtividade) está associado a um conjunto de inovações, temos configurado um processo de "destruição criadora" (Schumpeter), que impulsiona um novo ciclo de desenvolvimento. Em segundo lugar, o progresso técnico pode ser classificado em três categorias: (a) poupador de trabalho, com incremento de capital; (b) poupador de capital, com a instalação de máquinas mais eficientes; e (c) neutro (Hicks e Harrod). Por último, como consequiência das decisões relativas às variáveis lucratividade e custos, temos uma possibilidade de "escolha de técnicas", conforme pode ser demonstrada pelo Teorema de Okishio.

2 Definição adaptada da revista Public Management, june, 2001: 5.

3 Website: http://www.socinfo.org.br/.

4 Website: http://www.governoeletronico.gov.br/arquivos/. proposta de politica de governo eletronico.pdf.

5 Website: http://www.governoeletronico.gov.br/.

6 Website: http://www.brasil.gov.br/.

7 Website: http://www.redegoverno.gov.br/. Este portal de serviços, além de uma ferramenta de busca, é organizado em 31 áreas temáticas.

8 Revista TEMA, v. XXV, n.153, p. 15.

9 Tradução do título original "Building the Information Society: Moving Canada into the $21^{\text {st }}$ Century", disponível na Internet no endereço eletrônico: http://strategis.ic.gc.cal SSG/ih01103e.html.

10 Website: $\mathrm{http}: / /$ strategis.ic.gc.ca/SSG/ih01621e.html.

11 Website: http://canworknet.ingenia.com/canworknet.

12 Website: http://www.canada.gc.cal.

13 Website: http://www.accenture.com/.

14 Tradução do título original "eGovernment Leadership: Rhetoric vs Reality - Closing the Gap", disponível na Internet no endereço eletrônico: http://www.accenture.com/ $\underline{x d / x d . a s p ? i t=e n w e b \& x d=i n d u s t r i e s \backslash g o v e r n m e n t \mid g o v e ~ s t u d y . x m l . ~}$

15 Tradução do título original "The Singapore eGovernment Action Plan", disponível na Internet no endereço eletrônico: http://www.ida.gov.sg/Website/IDAContent.nsf/ vSubCat/Government+ComputerisationThe+Singapore+e-Government+Action+ Plan?OpenDocument.

16 Website: http://www.ida.gov.sg/.

17 Website: http://www.gov.sg/ps21/.

18 Website: http://www.gov.sg/.

19 Website: http://www.ecitizen.gov.sg/.

20 Os life events mencionados estão, atualmente, subordinados às seguintes áreas temáticas: (a) assuntos domésticos; (b) defesa; (c) educação; (d) emprego; (e) família; (f) justiça; (g) negócios; (h) saúde; e (i) transporte.

21 Website: http://shop.gov.sg/.

22 Website: $\mathrm{http} / / / \mathrm{www} . \mathrm{gov} . \mathrm{sg} / \mathrm{psd} / \mathrm{ps} 21 / \mathrm{lo} / \mathrm{index} \cdot \mathrm{html}$.

23 Tradução do título original "Modernising Government White Paper", disponível na Internet no endereço eletrônico http://www.official-documents.co.uk/document/cm43/ $\underline{4310 / 4310 . h t m}$. 
24 Tradução do título original "e-Government — A Strategic Framework for Public Services in the Information Age", disponível na Internet no endereço eletrônico http:/ /www.iagchampions.gov.uk/Strategy.htm.

25 Tradução do título original "Developing $21^{\text {st }}$ Century Skills", disponível na Internet no endereço eletrônico http://www.central-gov-nto.org.uk/library/docs/pdf/ swdp march2001.pdf.

26 Website: www.ukonline.gov.uk.

27 Os commom events mencionados estão, atualmente, organizados da seguinte forma: (a) viajando; (b) lidando com o crime; (c) ganhando um nenê; (d) fazendo mudanças; (e) aprendendo a dirigir; (f) morte e luto; (g) buscando alguém; e (h) procurando por emprego.

28 Website: http://www.receita.fazenda.gov.br/.

29 Website: http://www.mpas.gov.br/.

30 Musa cibernética do game Tomb Raider.

31 Bellamy (1999: 90).

32 Empirical paradox de Pinsonneault \& Kraemer (1993).

33 Estudos de Brynjolfsson, Malone \& Gurbaxani (1988), Whistler (1970) e Hoos (1960) indicam uma redução nos quadros gerenciais médios e os estudos de Pfeiffer \& Leiblebici (1977), Blau et al. (1976), Meyer (1968) e Lee (1964) apontam para o aumento destes mesmos quadros.

34 "Furthermore, given that public organizations rarely have tangible outcomes or output, measuring performance in public sector is extremely difficult" Heintze \& Bretchschneider (2000: 806).

35 Website: http://www.e-envoy.gov.uk/publications/guidelines/skills/skills.htm.

${ }^{36}$ Estrategias de promoción para la Sociedad de la Información: hacia un marco analítico, de Jacint Jordada.

37 Lachance (2000: 6).

\section{|Anexo}

\section{Questionário}

1) Qual a área responsável pela gestão do assunto governo eletrônico na sua organização?

2) Como ocorreu o processo de planejamento, de negociação e de implantação das soluções de governo eletrônico, no âmbito de sua organização?

3) Quais os principais objetivos a serem atingidos durante a fase de planejamento (prestação de informações e serviços, transparência, melhoria da qualidade, maior eficiência, redução de tempo de espera para atendimento)? Descrever indicadores.

4) Que experiências foram tomadas como modelo para a implantação da solução de $e$-gov na sua organização? 
5) Houve ação de planejamento e análise para a racionalização e a reformulação de processos ou houve uma simples transposição de ações de um ambiente para outro? Descrever.

6) Quais as principais mudanças observadas nos macroprocessos e ações da organização?

Descrever impactos e indicadores do sistema de gestão de processos e de resultados.

7) Houve processo de identificação de perfis profissionais, adequação, reciclagem, treinamento, capacitação e qualificação de capital humano? Descrever principais ações.

8) Quais as principais alterações notadas no perfil de competências (e.g. capacidade de interação com pessoal de áreas gerenciais ou técnicas) e nos ambientes de trabalho da organização?

9) Houve alteração no quantitativo de postos de trabalho das áreas? Descrever diretrizes da organização ou soluções encontradas.

10) Houve ou há experimentos na área de teletrabalho, de implantação de horários flexíveis ou inovações na forma de organização das equipes de trabalho?

Descrever inter-relações com serviços $e$-gov.

11) Quais as alterações mais importantes referentes ao gerenciamento de pessal e de desempenho?

12) Informações adicionais.

\section{Referências bibliográficas}

ACCEnture. (2001), eGovernment Leadership: Rhetoric vs Reality - Closing the Gap. Chicago: Global eGovernment Services.

Bellamy, Christine. (1999), "Joining-Up Government in the UK: Towards Public Services for an Information Age”. Australian Journal of Public Administration, v. 58, n. 3.

Blau, P. M., McHugh, C., Falbe, W., McKinkey, W., Tracy, P. K. (1976), Technology and Organization in Manufacturing. Administrative Science Quarterly, v. 21, n. 1.

Brasil. (2000), Proposta de Política de Governo Eletrônico para o Poder Executivo Federal. Brasília: Comitê Executivo do Governo Eletrônico. (2000), Sociedade da Informação no Brasil - Livro Verde. Brasília: Ministério da Ciência e Tecnologia.

Brynjolfsson, E., M alone, T. W., Gurbaxani, V. (1988), Markets and Hierarchies and the Impact of Information Technologies. Boston: Sloan School of Management, MIT.

Campillo, Marcia; Garza, Enrique de la. (1998), ¿Hacia dónde va el trabajo humano? Nueva Sociedad, n.70.

CAnada. (1996), Building the Information Society: Moving Canada into the $21^{\text {st }}$ Century. Ottawa: Minister of Supply and Services Canada.

(1997), The Impact of the Information Highway on the Workplace. Ottawa: Steering Committee on Workplace Issues and Lifelong Learning/Information Highway Advisory Council. 

Highway Advisory Council.

Cingapura. (2000), The Singapore eGovernment Action Plan. Singapore: Infocomm Development Authority of Singapore.

Cox, W. Michael. (1993), Technological Unemployment. Dallas: Federal Reserve Bank of Dallas.

Heintze, Theresa; BretschneIder, Stuart. (2000), "Information Technology and Restructuring in Public Organizations: Does Adoption of Information Technology Affect Organizational Structures, Communications and Decision Making?" Syracuse: Journal of Public Administration Research and Theory, October, p. 801-830.

Hoos, I. R. (1960), When the Computer Takes Over the Office. Harvard Business Review, v. 38, n. 4 .

JoRDANA, Jacint. (2000), "Estrategias de promoción para la Sociedad de la Información: hacia un marco analítico". Revista del CLAD Reforma y Democracia, n. 18, Octubre. p.155-180.

Lachance, Janice R. (2000), "The Dinosaur Killer: Moving Federal HRM into the new Millennium". The Public Manager, Winter1999-2000.

LeE, H. C. (1964), On Information Technology and Organization Structure. Academy of Management, v. 7, n. 3.

Meyer, M. W. (1968), "Automation and Bureaucratic Structure". American Journal of Sociology, v. 74, n. 3.

Norris, Donald; Fletcher, Patricia; Holden, Stephen. (2001), Is Your Local Government Plugged In? Washington, D.C.: Public Management, June, p.4-8.

Pfeiffer, J., Leiblebici, H. (1977), Information Technology and Organizational Structures. Pacific Sociological Review, v. 20, n. 2.

Pinsonneault, A., Kraemer, K. L. (1993), The Impact of Information Technology on Middle Managers. MIS Quarterly, v. 17, n. 3.

Reino Unido. (1999). Modernising Government White Paper. London: Cabinet Office. (2000), E-business Skills Assessment Toolkit. London: Cabinet Office. (2000), E-government - A Strategic Framework for Public Services in the Information Age. London: Cabinet Office. (2000), Skills for an Information Age Government. London: Cabinet Office. (2000), Successful IT: Modernising Government in Action. London: Cabinet

Office.

. (2001), Developing $21^{\text {st }}$ Century Skills. London: Central Government National Training Organization.

Serviço Federal de Processamento de Dados. (2001), "Governo Eletrônico, Informação Pública e Gratuita, Brasília”: in Revista TEMA, v. XXV, n.153, Janeiro/Fevereiro, p. 64.

Whistler, T. (1970) The Impact of Computers on Organizations. New York: Praeger. 


\section{Governo eletrônico e seus impactos na estrutura e na força de trabalho das organizações públicas \\ Espartaco Madureira Coelho}

Este artigo tem por objetivo apresentar uma revisão dos programas e das ações empreendidas pelo governo eletrônico do Brasil, Canadá, Cingapura e Reino Unido, no que tange a novas formas de trabalho e à aquisição de novos conhecimentos por parte de seu corpo funcional. Também são examinados os impactos sobre os processos organizacionais e sobre a força de trabalho em duas organizações públicas brasileiras - a Secretaria da Receita Federal (SRF) e o Instituto Nacional de Seguridade Social (INSS) - que, atualmente, ocupam posição de destaque na utilização das novas Tecnologias da Informação e de Comunicações (TIC).

A metodologia empregada na primeira parte do trabalho, referente às propostas e às ações dos programas de governo eletrônico de quatro países foi a de pesquisa bibliográfica e em referências no próprio ambiente Internet.

Em relação à segunda parte, referente à descrição dos efeitos das soluções de governo eletrônico nas duas organizações públicas acima citadas, foram realizadas visitas às dependências destas entidades e, após o registro das informações relativas à implantação de procedimentos no âmbito do governo eletrônico, foi feita entrevista baseada nas questões apresentadas no questionário constante do Anexo.

\section{Gobierno electrónico y sus impactos en la estructura y la fuerza de trabajo de las organizaciones públicas}

Espartaco Madureira Coelho

Este artículo tiene como objetivo presente una caminata a través de los programas y de las acciones emprendidos por el gobierno electrónico del Brasil, de Canadá, de Cingapura y de Reino Unido, en que refiere a las nuevas formas de trabajo y a la adquisición del nuevo conocimiento de parte de su cuerpo funcional. También los impactos en los procesos de organización y la fuerza de trabajo en dos organizaciones públicas brasileñas se examinan.

La Secretaria da Receita Federal - SRF (Secretaría del Rédito Federal) y del Instituto Nacional de Seguridade Social — INSS (Instituto Nacional de la Seguridad Social).

Actualmente, estas organizaciones ocupán posición de prominencia en el uso de las nuevas Tecnologías de la Información y Comunicaciones (TIC). La metodología usada en la primera parte del trabajo, refiriendo a las ofertas y a las acciones de los programas del gobierno electrónico de cuatro países fue de investigación bibliográfica y en referencias en el ambiente Internet apropiado.

En lo referente a la segunda parte, una descripción de los efectos de la solución de gobierno electrónico en las dos organizaciónes públicas sobre citadas, fueran visitadas las dependencias de estas entidades y, después de registradas las informaciónes relativas a la implantación de los procedimiento del gobierno electrónico, fueran hechas entrevistas basadas en preguntas constantes del cuestionario Anexo.

\section{Electronic government and its impacts in the structure and the work force of the public organizations}

Espartaco Madureira Coelho

This article has for objective to present a walk through of the programs and the actions undertaken by the electronic government of Brazil, Canada, Cingapura and United Kingdom, in that it refers to the new forms of work and to the acquisition of new knowledge on the part of its functional body. Also the impacts on the organizational processes and the work
Revista do

Serviço

Público

Ano 52

Número 2

Abr-Jun 2001

Espartaco

Madureira

Coelho é

economista e

especialista em

políticas

públicas e

gestão

governamental, atualmente trabalhando na

Secretaria de

Gestão do

Ministério do

Planejamento,

Orçamento e

Gestão. 
force in two Brazilian public organizations are examined - Secretaria da Receita Federal - SRF (The Secretariat of Federal Revenue) and the Instituto Nacional de Seguridade Social - INSS (National Institute of Social Security).

Currently, they occupy position of proeminence in the use of the new Technologies of Information and Comumnications (TIC). The methodology used in the first part of the work, referring to the proposals and the actions of the programs of electronic government of four countries consisted on bibliographical research and in references in the proper Internet environment. In relation to the second part, referring to the description of the effect of the solutions of electronic government in the two public organizations above cited, they had been carried through visits to the dependences of these entities and, after the register of the relative information to the implantation of procedures in the scope of the electronic government, was made interview based on the questions presented in the constant questionnaire of Annex. 
A Revista do Serviço Público é uma publicação da ENAP Escola Nacional de Administração Pública, voltada para a divulgação e debate de temas relacionados ao Estado, à Administração Pública e à gestão governamental. Procurando o aprimoramento permanente da revista, tanto no seu conteúdo quanto na apresentação gráfica, pedimos aos nossos colaboradores a observação das normas abaixo descritas.

\section{Normas para os colaboradores}

1. Os artigos, sempre inéditos no Brasil, devem conter em torno de 25 laudas de 20 linhas de 70 toques.

2. Os originais devem ser encaminhados ao editor, em arquivo digital, em programa de uso universal e enviados para editora@enap.gov.br . Usar apenas as formatações-padrão.

3. Cada artigo deve vir acompanhado de um resumo analítico em português, espanhol e inglês, de cerca de 150 palavras, que permita uma visão global e antecipada do assunto tratado.

4. Na primeira página do artigo, deve constar informação sobre formação e vinculação institucional do autor (em até duas linhas).

5. Notas, referências e bibliografia devem vir ao final do artigo, e não ao pé da página. Notas e referências, sendo o caso, devem vir devidamente numeradas.

6. Além de artigos, a revista receberá comunicações, notas informativas, notícias e relatórios conclusivos de pesquisas em desenvolvimento, com até 15 laudas. Resenhas de livros, em torno de 4 laudas, devem conter uma apresentação sucinta da obra e eventuais comentários que situem o leitor na discussão.

7. Os trabalhos que se adequarem à linha temática da revista serão apreciados pelo conselho editorial, que decidirá sobre a publicação com base em pareceres de consultores ad hoc.

8. Os originais enviados à Revista do Serviço Público não serão devolvidos. A revista compromete-se a informar os autores sobre a publicação ou não de seus trabalhos.

\section{Convite a resenhadores}

A Revista do Serviço Público convida todos os interessados em remeter resenhas de trabalhos publicados no Brasil e no exterior sobre Estado, Administração Pública e gestão governamental.

As resenhas devem ser originais e não exceder a cinco laudas datilografadas em espaço duplo com 20 linhas de 70 toques, e devem apresentar de modo sucinto a obra, com comentários que situem o leitor na discussão apresentada.

As resenhas devem ser enviadas em português, sem notas de rodapé, contendo o título completo e subtítulo do livro, nome completo do autor, local de publicação, editora e ano de publicação, bem como uma breve informação sobre a formação e vinculação institucional do resenhador (em até duas linhas), acompanhadas do respectivo disquete.

\section{Nota aos editores}

Pedimos encaminhar à Revista do Serviço Público exemplares de livros publicados, a fim de serem resenhados. Os resenhadores interessados receberão cópias dos livros enviados. 